\title{
Integrated analysis of miRNA and mRNA expression profiles in response to $\mathrm{Cd}$ exposure in rice seedlings
}

Mingfeng Tang ${ }^{1 \dagger}$, Donghai Mao ${ }^{1+}$, Liwei $\mathrm{Xu}^{1}$, Dayong $\mathrm{Li}^{2}$, Shuhui Song ${ }^{3}$ and Caiyan Chen ${ }^{{ }^{*}}$

\begin{abstract}
Background: Independent transcriptome profile analyses of miRNAs or mRNAs under conditions of cadmium (Cd) stress have been widely reported in plants. However, a combined analysis of sRNA sequencing expression data with miRNA target expression data to infer the relative activities of miRNAs that regulate gene expression changes resulting from $\mathrm{Cd}$ stress has not been reported in rice. To elucidate the roles played by miRNAs in the regulation of changes in gene expression in response to Cd stress in rice (Oryza sativa L.), we simultaneously characterized changes in the miRNA and mRNA profiles following treatment with $\mathrm{Cd}$.

Results: A total of 163 miRNAs and 2,574 mRNAs were identified to be differentially expressed under Cd stress, and the changes in the gene expression profile in the shoot were distinct from those in the root. At the miRNA level, 141 known miRNAs belonging to 48 families, and 39 known miRNAs in 23 families were identified to be differentially expressed in the root and shoot, respectively. In addition, we identified eight new miRNA candidates from the root and five from the shoot that were differentially expressed in response to $\mathrm{Cd}$ treatment. For the mRNAs, we identified 1,044 genes in the root and 448 genes in the shoot that were up-regulated, while 572 and 645 genes were down-regulated in the root and shoot, respectively. GO and KEGG enrichment analyses showed that genes encoding secondary, metabolite synthases, signaling molecules, and $A B C$ transporters were significantly enriched in the root, while only ribosomal protein and carotenoid biosynthesis genes were significantly enriched in the shoot. Then 10 known miRNA-mRNA interaction pairs and six new candidate ones, that showed the opposite expression patterns, were identified by aligning our two datasets against online databases and by using the UEA sRNA toolkit respectively.

Conclusions: This study is the first to use high throughput DNA sequencing to simultaneously detect changes in miRNA and mRNA expression patterns in the root and shoot in response to $\mathrm{Cd}$ treatment. These integrated high-throughput expression data provide a valuable resource to examine global genome expression changes in response to $\mathrm{Cd}$ treatment and how these are regulated by miRNAs.
\end{abstract}

Keywords: Cd stress, miRNA, mRNA, High-throughput deep sequencing, Rice

\section{Background}

Cadmium (Cd) is a well-known environmental toxicant to humans and plants. Cd has been implicated as a potential cause of prostate, lung, and testicular cancer, kidney tubule damage, bone fractures, and osteomalacia that is acquired from consuming contaminated crops

\footnotetext{
* Correspondence: cychen@isa.ac.cn

${ }^{\dagger}$ Equal contributors

'Key Laboratory of Agro-ecological Processes in Subtropical Region, Institute of Subtropical Agriculture, Chinese Academy of Sciences, Changsha 410125, China

Full list of author information is available at the end of the article
}

[1,2]. Because of widespread Cd pollution in paddy soils and its ready accumulation in crops, people who consume Cd-contaminated foods are inevitably exposed to significant amounts of $\mathrm{Cd}$ [3]. $\mathrm{Cd}$ is a non-essential element for plants that reduces crop quality and, subsequently, food safety at low concentrations, and damages plant growth and reproduction at high concentrations. Therefore, elucidating the physiological, genetic, and molecular responses to $\mathrm{Cd}$ stress will be of benefit in improving both crop yield and quality.

MicroRNAs (miRNA) are a class of small non-coding RNAs (approximately $21 \mathrm{nt}$ long) that bind complementary 
sequences in target mRNAs to specifically regulate gene expression through either mRNA degradation or translational inhibition [4]. Plant miRNAs are involved in regulating a wide range of biological processes, including signal transduction, cell identity, growth, and developmental patterning [5-7]. Furthermore, numerous miRNAs have also been reported to be involved in biotic and abiotic stress responses [8-12]. Based on microarray data, the expression of 14 stress-regulated miRNAs was observed under salt, drought, and cold stresses; miR168, miR171, and miR396 showed responses to all three stress treatments [12]. Induction of miR395 and miR399 was observed in response to sulfate and phosphate deprivation, respectively $[10,11]$. Under conditions of copper $(\mathrm{Cu})$ deficiency, up-regulation of miR398 expression to decrease levels of $\mathrm{Cu} / \mathrm{Zn}$ superoxide dismutases $1(\mathrm{CSD} 1)$ and $\mathrm{Cu} / \mathrm{Zn}$ superoxide dismutases 2 (CSD2) is important to ensure that the limited amount of $\mathrm{Cu}$ is present to support necessary biological processes. However, when exposed to high levels of $\mathrm{Cu}$, the induction of CSD1 and CSD 2 mRNA by the down-regulation of miR398 is necessary to activate antioxidant systems [8,9]. A group of miRNAs have been identified to be $\mathrm{Cd}-$ responsive in rice, Medicago truncatula, and Arabidopsis thaliana [13-16]. Huang et al. [14] isolated 28 novel miRNAs from a small RNA library prepared from Cd-treated rice seedlings [14]. Ding et al. [13] identified 19 miRNAs that were induced in rice roots in response to $\mathrm{Cd}$ treatment in a microarray-based assay [13]. Most recently, a total of $12 \mathrm{Cd}$-responsive miRNAs predicted previously were validated using microarray assays in rice [15]. A qRT-PCR-based assay for the expression of miRNAs under Cd stress in M. truncatula found that miR393, miR171, miR319, and miR529 were up-regulated, whereas miR166 and miR398 were down-regulated [16].

Previous studies have investigated physiological mechanisms underlying the response to $\mathrm{Cd}$ stress. $\mathrm{Cd}$ can induce oxidative stress and activate the expression of antioxidant enzymes [17-19]. Plants produce cysteine-rich (Cys-rich) peptides that chelate $\mathrm{Cd}$ to form non-toxic complexes which are then sequestered into the vacuole to avoid high levels of free cytotoxic $\mathrm{Cd}$ in the cytosol. The enzymatically-synthesized glutathione, phytochelatins (PCs), and the gene-encoded metallothioneins (MTs) are the main Cys-rich peptides [20-22]. Using a $22 \mathrm{~K}$ microarray covering 21,495 genes, Ogawa et al. [23] investigated gene regulation under $\mathrm{Cd}$ stress in rice and found sets of genes that were induced, including cytochrome P450 family proteins, heat shock proteins, glutathione S-transferase, transcription factors, protein kinases, and some transporter genes. Herbette et al. [17] also found that genes involved in sulfur assimilation-reduction, glutathione (GSH) metabolism, and the biosynthesis of phenylpropanoids were induced during $\mathrm{Cd}$ stress in A. thaliana roots.
Independent transcriptome profiling of miRNAs or mRNAs under various stress conditions has been widely reported. In addition, several studies have reported combined analyses of sRNA sequencing expression data with miRNA target expression and/or degradome data to infer the relative activities of miRNAs associated with heavy metal stress [24,25]. However, no such combined analysis has been reported for Cd stress in rice. Because the expression of miRNAs and mRNAs are spatiotemporally regulated independently, it remains to be elucidated how mRNA profiles change in relation to miRNA regulation in a specific tissue or organ. In addition, because the total number of miRNAs discovered in plant genomes continues to increase with advances in genomics, there are still many novel miRNAs involved in stress responses and/or developmental regulation to be identified.

To acquire a deep understanding of the changes in the transcriptome that occur in response to $\mathrm{Cd}$ stress in rice, we used high-throughput sequencing technology to simultaneously analyze miRNA and mRNA expression profiles in Cd-stressed rice seedlings. We combined these two datasets through two online databases and identified a total of 16 miRNA-mRNA interaction pairs in root, including six new miRNA candidates and their targets, exhibiting inverted patterns of relative expression. These highthroughput expression data provide a valuable resource to examine global genome expression changes in response to $\mathrm{Cd}$ treatment and how these are regulated by miRNAs.

\section{Methods}

\section{Plant growth conditions and treatments}

Seeds of the rice cultivar Nipponbare (Oryza sativa L. ssp japonica $\mathrm{cv}$. 'Nipponbare') were surface sterilized with 3\% sodium hypochlorite, rinsed five times with distilled water, immersed in distilled water for two days, and then allowed to germinate for another two days at $37^{\circ} \mathrm{C}$. Seedlings were grown in half-strength rice growth nutrient solution under a 13 -h light $\left(28^{\circ} \mathrm{C}\right) / 11$-h dark $\left(25^{\circ} \mathrm{C}\right)$ photoperiod. Sevenday-old seedlings were exposed to treatments with and without $60 \mu \mathrm{M} \mathrm{CdCl}_{2}$, and the roots and shoots were then collected separately after $6 \mathrm{~h}[13,15,17]$. The collected samples were frozen in liquid nitrogen immediately and stored at $-80^{\circ} \mathrm{C}$ until use.

\section{RNA isolation}

Total RNA was isolated using $\mathrm{TRIzol}^{\bullet}$ reagent (Invitrogen, Carlsbad, CA, USA). The RNA quality was assessed on agarose gels and the concentration was determined with a NanoDrop spectrophotometer (ND-1000, NamedropsTechnologies, Wilmington, DE, USA).

\section{MiRNA sequencing and analysis}

Four small RNA libraries were constructed, amplified, and sequenced as previously described [26-28]. The samples 
treated with $\mathrm{CdCl}_{2}$ were called $\mathrm{CR}$ and $\mathrm{CS}$, where ' $\mathrm{R}$ ' indicates the root tissue, and ' $\mathrm{S}$ ' indicates the shoot tissue. The control samples, which were not treated with $\mathrm{CdCl}_{2}$, were called KR and KS, respectively. To evaluate the reproducibility of the data, we constructed another library from root tissue treated with $\mathrm{CdCl}_{2}$ and called it CR2. Thus, we had a total of five libraries in our analysis: KR, CR, KS, CS, and CR2. Small RNAs of 18-30 nt was gel-purified, 5' and 3' adaptors were ligated sequentially to the small RNAs, and reverse transcription was then performed. The amplified fragments were sequenced on an Illumina Hiseq 2000 instrument at BGI Tech in Shenzhen, China, according to the manufacturer's protocol.

After removing the adaptor sequences, low-quality tags, contaminants, and reads shorter than $18 \mathrm{nt}$, the clean reads in the five libraries were mapped to the rice genome using SOAP2[29]. rRNA, scRNA, snoRNA, snRNA, tRNA, exon, intron, and repeats sequence tags were removed based on Rfam(10.1) database(http://rfam. sanger.ac.uk/) [30] and NCBI Genbank database (http:// www.ncbi.nlm.nih.gov/) searches. Conserved miRNAs were identified through a Blastn search against the miRNA database, miRBase 19.0 (http://www.mirbase. org/) [31,32]. For new miRNA candidates, we used the miRNA prediction software Mireap (http://sourceforge. net/projects/mireap/) [33]. For predicting the targets of new miRNA candidates, we used a plant target prediction tool available in the University of East Anglia (UEA) sRNA toolkit (http://srna-workbench.cmp.uea.ac.uk/) [34].

\section{Differential gene expression (DGE) library construction and Illumina sequencing}

The DGE libraries for five samples were processed in parallel using Illumina sample preparation kits. Briefly, mRNA was captured from total RNA of each sample with magnetic oligo (dT) beads. Following first and second strand cDNA synthesis, Endonuclease NlaIII was used to digest the bead-bound cDNA, and bound fragments containing a CATG sequence site adjacent to the poly (A) tail at the 3 ' end were acquired. After precipitation of the 3' cDNA fragment, Illumina adaptor 1 was added to the 5 ' end; this adaptor contains a recognition site for the endonuclease MmeI to cut 17 bp downstream of the recognition site (CTAG) and produce 17 bp tags with adaptor 1 . Illumina adapter 2 was introduced at the site of MmeI cleavage after removing the 3' fragment via magnetic bead precipitation. The tags with both adapter 1 and adapter 2 were then prepared for Illumina DNA sequencing [35].

\section{Identification of differentially-expressed genes}

Before comparing the differential expression of genes in response to $\mathrm{Cd}$ treatment, normalized gene expression levels were obtained by normalizing the number of raw clean tags in each library to the number of transcripts per million clean tags (TPM). A rigorous algorithm method was performed for the differential expression detection of genes across samples. A combination of FDR $<0.001$ and the absolute value of $\log _{2}$ Ratio $\geq 1$ were used as the threshold to determine the significance of differentially-expressed genes. GO and pathway enrichment analysis were based on the agriGO (http://bioinfo. cau.edu.cn/agriGO/index.php) [36] and KEGG pathways (http://www.genome.jp/kegg/) [37,38]. Cluster analysis was performed with CLUSTER3.0 and viewed with the TREEVIEW software program (http://rana.lbl.gov/ EisenSoftware.htm) [39].

\section{Quantitative reverse transcription polymerase chain reaction (qRT-PCR) analysis of gene expression}

To validate the sequencing data, we first randomly choose 20 differentially-expressed mRNAs and 10 miRNAs for quantitative real-time RT-PCR (qRT-PCR) analysis (Additional file 1: Figure S2; Additional file 2: Table S10). We then validated the expression data of 41 key Cdresponsive genes including transcription factors, kinase, and metabolic enzymes by the same method (Additional file 2: Table S10). For mRNA quantification, after acquiring high quality total RNA, SuperSript ${ }^{\mathrm{m}}$ II Reverse Transcriptase (Invitrogen, USA) and Oligo(dT) primers were used to synthesis first-strand cDNA. The qRT-PCR were performed using gene-specific primers (Additional file 3: Table S11) in a total volume of $20 \mu \mathrm{L}$ as follows: $10 \mu \mathrm{L}$ SYBR Premix Ex Taq ${ }^{\text {Ta }}$ Perfect Time(TaKaRa, Japan), $0.4 \mu \mathrm{L}$ ROX Reference Dye, $4 \mu \mathrm{L}$ primer mix (1:1 mix of forward and reverse primers at $2.5 \mu \mathrm{mol} / \mu \mathrm{L}$ each), $5.6 \mu \mathrm{L}$ of a one-third dilution of the cDNAs as template. The reaction conditions were: $30 \mathrm{~s}$ at $95^{\circ} \mathrm{C}$ followed by 40 cycles of $30 \mathrm{~s}$ at $95^{\circ} \mathrm{C}$, and $30 \mathrm{~s}$ at $60^{\circ} \mathrm{C}$. The rice UBC was used as an internal standard. For mature miRNA quantification, the miScript II RT kit was used to reverse transcribe mature miRNAs according to the manufacturer's instructions (Qiagen, Germany). The miScript SYBR Green PCR kit (Qiagen), containing QuantiTect SYBR Green PCR Master Mix and the miScript Universal Primer with the miRNA-specific forward primer (Additional file 3: Table S11) was used to quantify mature miRNAs. The rice U6 RNA was used as the internal control for RNA template normalization. All mRNA and miRNA relative expression levels were calculated by the comparative $\mathrm{Ct}$ method. At least three independent biological replicates were used for each gene.

\section{Results}

Construction and sequencing of small RNA libraries

A total of four small RNA libraries were constructed with root and shoot tissues from 7-day-old rice seedlings exposed to solutions with and without $60 \mu \mathrm{M} \mathrm{CdCl}_{2}$ for 
6 h. We obtained 21,390,618, 21,765,186, 17,596,690, and 21,791,505 high quality reads from the KR, CR, $\mathrm{KS}$, and CS libraries, respectively (Additional file 4: Table S1). After removing the adaptor sequences, lowquality tags, contaminants, and reads of $<18 \mathrm{nt}$, a total of 20,686,970, 21,514,502, 17,453,217, and 21,688,526 clean reads remained from the KR, CR, KS, and CS libraries, respectively (Additional file 4: Table S1). We then aligned all reads against the rice genome using SOAP2; 14,047,474, 11,365,132,16,402,547, and 20,305,183 reads from the KR, CR, KS, and CS libraries, respectively, gave perfect matches to the rice genome sequence, representing $67.9 \%, 52.83 \%, 93.98 \%$, and $93.62 \%$ of the total reads in the four libraries. The distribution of small RNAs among the different categories is summarized in Additional file 5: Table S2. The un-annotated reads comprised most of the total reads and accounted for $30 \sim 50 \%$ of the total reads in the four libraries. Approximately $0.13 \%$ (KR), $0.1 \%$ (CR), $0.14 \%(\mathrm{KS})$ and $0.12 \%$ (CS) of the unique reads matched miRNAs. The length distribution of the small RNAs ranged from 10 to $30 \mathrm{nt}$ (Figure 1). In the four libraries, $24 \mathrm{nt}$ and $21 \mathrm{nt}$ small RNAs were the main size classes and accounted for about $50 \%$ of the population, followed by $22 \mathrm{nt}$ and $23 \mathrm{nt}$ small RNAs.

\section{MicroRNA profiling of rice under $\mathrm{Cd}$ stress}

The expression of miRNAs in the Cd-treated and control groups was shown by calculating the $\log _{2}$ Ratio. Using $\mid \log _{2}$ Ratio $\mid \geq 1$ and $P<0.05$ as the cut-off, we identified 163 differentially expressed known rice miRNAs in our pair wise comparisons, including 121 downregulated and 20 up-regulated in root (CR/KR), and 37 down-regulated and two up-regulated in the shoot (CS/KS) (Figure 2A and Additional file 6: Table S3 and Additional file 7: Table S4). A Venn diagram (Figure 2B) showed that the relative expression of 17 miRNAs changed in both the root and the shoot; all 17 were downregulated except for miR156k and miR529a in the shoot and miRNA169i-3p in the root, which were up-regulated (Figure 2C).
In addition to analyzing the expression of known miRNAs, we predicted new miRNA candidates using the miRNA prediction software Mireap (http://sourceforge. net/projects/mireap/) [33]. By exploring the secondary structure, Dicer cleavage sites, and the minimum free energy of the un-annotated small RNA tags that could be mapped to rice genome, we predicted 137, 69, 154, and 165 new miRNA candidates from the KR, CR, KS, and CS libraries, respectively (Additional file 8: Tables S5). Using the same criteria $\left(\mid \log _{2}\right.$ Ratio $\left.\mid \geq 1, \mathrm{P}<0.05\right)$ to determine differentially-expressed miRNAs, we found eight differentially-expressed miRNAs in the root and five differentially-expressed miRNAs in the shoot (Table 1). The precursor sequences of these new miRNA candidates varied from 77 to $260 \mathrm{nt}$ in length, and they formed proper predicted secondary hairpin structures with MEFIs ranging from -27.6 to $-149 \mathrm{kcal} / \mathrm{mol}$ (Additional file 9: Table S6). Except for three of the new miRNA genes that are located within genes, all the others are situated in intergenic regions (Additional file 9: Table S6). Most of the mature miRNA sequences are in the $5^{\prime}$ arm of the stemloop sequences, and only three miRNAs were found in the 3' arms. As for expression patterns, one of the eight differentially-expressed root miRNAs and three of the five differentially-expressed shoot miRNAs were up-regulated, while all of the others were down-regulated.

\section{Global mRNA expression profiles in the rice root and shoot in response to $\mathrm{Cd}$ stress}

In order to identify all miRNA targets that are differentially expressed in response to Cd stress, we used the Solexa Genome Analyzer to perform high-throughput Tag-seq analysis on rice root and shoot RNA libraries. These libraries were constructed from the same 7-dayold rice seedlings that were exposed to $60 \mu \mathrm{M} \mathrm{CdCl}_{2}$ for $6 \mathrm{~h}$ (and the control solution without $\mathrm{CdCl}_{2}$ ) and the same total RNAs were used for small RNA sequencing. The major characteristics of these four libraries are summarized in Table 2. Approximately 5.7 to 6.1 million total sequence tags per library were obtained, with 20,000 to 70,000 distinct tag sequences. Approximately

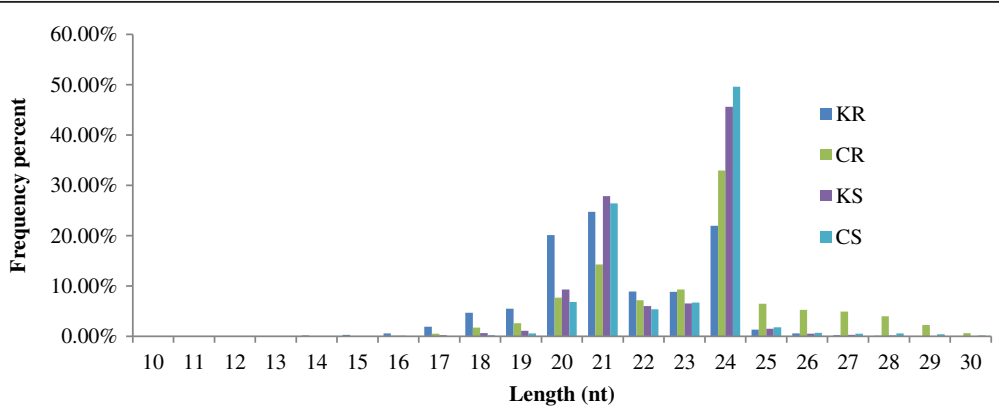

Figure 1 Length distribution of tags in the small RNA libraries. 


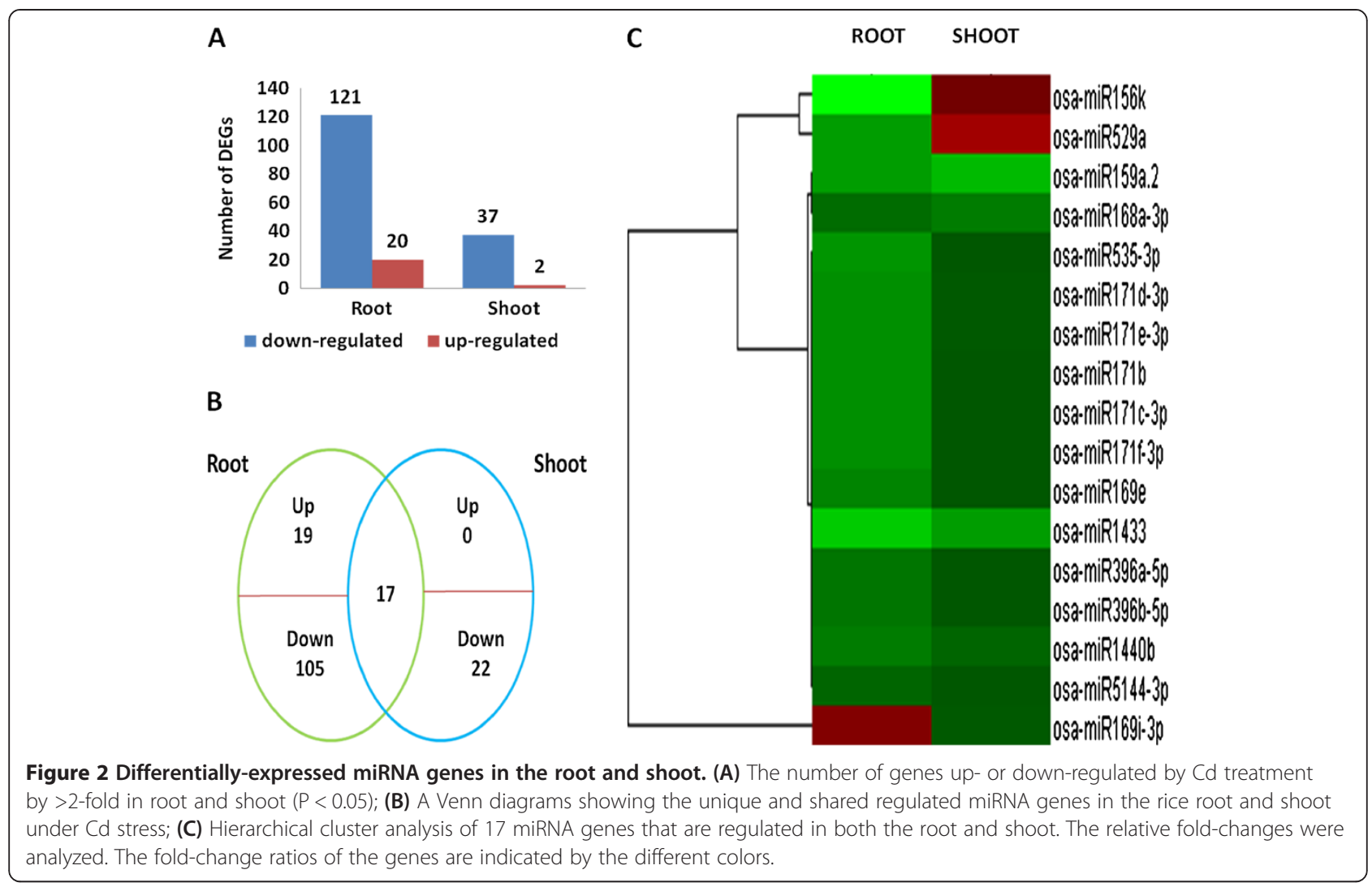

5.3 to 5.9 million total clean sequence tags per library, with 1.1 to 2.3 million distinct clean tag sequences, were produced after filtering out low-quality tags, unexpected-length tags, and single-copy tags. Finally, we obtained 187,698, 218,366, 110,103 and 114,495 unique tags for the KR, CR, KS, and CS libraries, respectively.
Saturation analysis was applied to estimate whether or not new unique tags can be detected with increases in the total number of tags. As shown in Additional file 10: Figure S1, the number of unique tags increased with the total number of tags and reached a plateau shortly after 1 million tags; no new unique tag was identified as the

Table 1 New miRNA candidates differentially expressed in root and shoot under Cd stress

\begin{tabular}{|c|c|c|c|c|c|c|}
\hline Name & Chromosome & Arm & Mature sequence $\left(5^{\prime}-3^{\prime}\right)$ & $L(n t)$ & log2 Ratio & $\overline{\text { P-value }}$ \\
\hline miRR1 & 6 & $5 p$ & AGAAGAGTGGGAACGTGGGCTT & 22 & -1.59 & 0.00 \\
\hline miRR2 & 3 & $5 p$ & AGGCGGCGGGGTGGGTGACGGT & 22 & -1.39 & 0.01 \\
\hline miRR3 & 2 & $5 p$ & AGGCGGGGAGACCGGCGAGCA & 21 & -1.13 & 0.01 \\
\hline miRR4 & 7 & $5 p$ & ATTGAGGAGATTGGGAAGATT & 21 & -1.3 & 0.00 \\
\hline miRR5 & 3 & $3 p$ & CATGTTTGGGGATGGAGGTAG & 21 & -1.69 & 0.00 \\
\hline miRR6 & 11 & $3 p$ & CTITGAGTAGGGTCTAAACAGAG & 23 & 2.06 & 0.00 \\
\hline miRR7 & 12 & $5 p$ & GTGGGGCGGCGGTGGTGGCGG & 21 & -1.08 & 0.00 \\
\hline miRR8 & 2 & $5 p$ & TAAAGGAAGAAGAGAGAGAGT & 21 & -2.12 & 0.00 \\
\hline miRS1 & 1 & $5 p$ & CGGCGTCGTCTAGGCCGAGCGG & 22 & 1.49 & 0.02 \\
\hline miRS2 & 11 & $3 p$ & CGTGGTGCGGTGCGGCGGCGG & 21 & 1.21 & 0.04 \\
\hline miRS3 & 6 & $5 p$ & GACGGAGGGAGTAGAGTAGAAGA & 23 & 1.4 & 0.03 \\
\hline miRS4 & 6 & $5 p$ & TCGCCGCGGCTGGCATCAGCA & 21 & -1.17 & 0.01 \\
\hline miRS5 & 6 & $5 p$ & TGCAGCTGACATGGCATGCCA & 21 & -1.51 & 0.00 \\
\hline
\end{tabular}


Table 2 Categorization and abundance of tags

\begin{tabular}{|c|c|c|c|c|c|}
\hline & & KR & CR & KS & CS \\
\hline \multirow[t]{2}{*}{ Raw data } & Total & 5786951 & 5890800 & 6035079 & 5775616 \\
\hline & Distinct tags & 518942 & 628484 & 252376 & 258567 \\
\hline \multirow[t]{2}{*}{ Clean tags } & Total number & 5454707 & 5479746 & 5890736 & 5629573 \\
\hline & Distinct tag numbers & 187698 & 218366 & 110103 & 114495 \\
\hline \multirow[t]{4}{*}{ All tag mapping to gene } & Total number & 3814923 & 3717042 & 4938104 & 4600158 \\
\hline & Total\% of clean tags & $69.94 \%$ & $67.83 \%$ & $83.83 \%$ & $81.71 \%$ \\
\hline & Distinct tag numbers & 75809 & 80554 & 70594 & 72224 \\
\hline & Distinct Tag\% of clean tags & $40.39 \%$ & $36.89 \%$ & $64.12 \%$ & $63.08 \%$ \\
\hline \multirow[t]{4}{*}{ Unambiguous tag mapping to gene } & Total number & 2401629 & 2399312 & 2650513 & 2448845 \\
\hline & Total\% of clean tags & $44.03 \%$ & $43.79 \%$ & $44.99 \%$ & $43.50 \%$ \\
\hline & Distinct tag numbers & 49474 & 53274 & 44370 & 45456 \\
\hline & Distinct Tag\% of clean tags & $26.36 \%$ & $24.40 \%$ & $40.30 \%$ & $39.70 \%$ \\
\hline \multirow[t]{2}{*}{ All tag-mapped genes } & Number & 32683 & 33502 & 31136 & 31129 \\
\hline & $\%$ of ref genes & $49.27 \%$ & $50.50 \%$ & $46.94 \%$ & $46.92 \%$ \\
\hline \multirow[t]{2}{*}{ Unambiguous tag-mapped genes } & Number & 16348 & 16888 & 14858 & 14830 \\
\hline & $\%$ of ref genes & $24.64 \%$ & $25.46 \%$ & $22.40 \%$ & $22.36 \%$ \\
\hline \multirow[t]{2}{*}{ Mapping to genome } & Total number & 574449 & 555079 & 491620 & 458005 \\
\hline & Total\% of clean tags & $10.53 \%$ & $10.13 \%$ & $8.35 \%$ & $8.14 \%$ \\
\hline \multirow[t]{2}{*}{ Unknown tags } & Total number & 1065335 & 1207625 & 461012 & 571410 \\
\hline & Total\% of clean tags & $19.53 \%$ & $22.04 \%$ & $7.83 \%$ & $10.15 \%$ \\
\hline
\end{tabular}

total number approached 2 million. Therefore, the four libraries are full representations of transcripts under the different treatments.

We annotated the sequence tags based on OsNipponbare-Reference-IRGSP-1.0 (http://rice.plantbiology. msu.edu/index.shtml) [40], and only the clean and unambiguous tags that matched perfectly or had only a single mismatch was analyzed further. Based on these criteria, 49,474 (26.36\% of the clean tags), 53,274 (24.40\% of the clean tags), $44,370(40.30 \%$ of the clean tags $)$ and 45,456 (39.70\% of the clean tags) of the tags in the KR, $\mathrm{CR}, \mathrm{KS}$, and CS libraries, respectively, were mapped unambiguously to the reference genes. Also, 555,079 (10.13\% of the clean tags), 574,758 (10.69\% of the clean tags), 491,620 (8.35\% of the clean tags) and 458,005 (8.14\% of the clean tags) unambiguous tags from these same libraries were matched to the reference genome database. However, 1,065,335 (19.53\% of the clean tags), $1,207,625$ (22.04\% of the clean tags), 461,012 (7.83\% of the clean tags) and 571,410 (10.15\% of the clean tags) did not map to the reference database from the $K R$, CR, KS, and CS libraries, respectively (Table 2).

Transcripts detected with at least two-fold differences ( $\mid \log _{2}$ Ratio $\mid \geq 1$ and FDR $<0.001$ ) in the Cd treatment libraries as compared with the control samples were included in our analysis to identify differentially expressed genes. There were 573 down-regulated and 1,046 upregulated genes in the root, and 645 down-regulated and 448 up-regulated genes in the shoot (Figure 3). These genes from the root and shoot were compared by Venn diagrams to identify genes that showed differences in expression between the two tissues. The number of $\mathrm{Cd}$ responsive genes in both the root and shoot was 135 , and these were divided into two groups with four clusters by their expression patterns; 952 genes were specifically up-regulated in the root and 387 specifically in the shoot, while 529 and 571 genes were specifically downregulated in the root and shoot, respectively.

In order to explore the functions of genes that are responsive to $\mathrm{Cd}$ treatment in the plant, gene ontology (GO) and pathway enrichment analysis were performed. GO categorization showed that the Cd stress-regulated genes in the root were enriched in metabolic and stressresponse processes (Figure 4A), while only genes involved in lipid metabolism were enriched in the shoot (Figure 4B), indicating the differences in the major processes that respond to $\mathrm{Cd}$ stress in the two tissues. Two molecular function GO terms, 'oxygen binding' and 'transcription factor activity', were significantly enriched in the root (Figure 4A), while only 'structural molecule activity' was enriched in the shoot (Figure 4B). The genes associated with cytoplasm, ribosomes, plastids, 


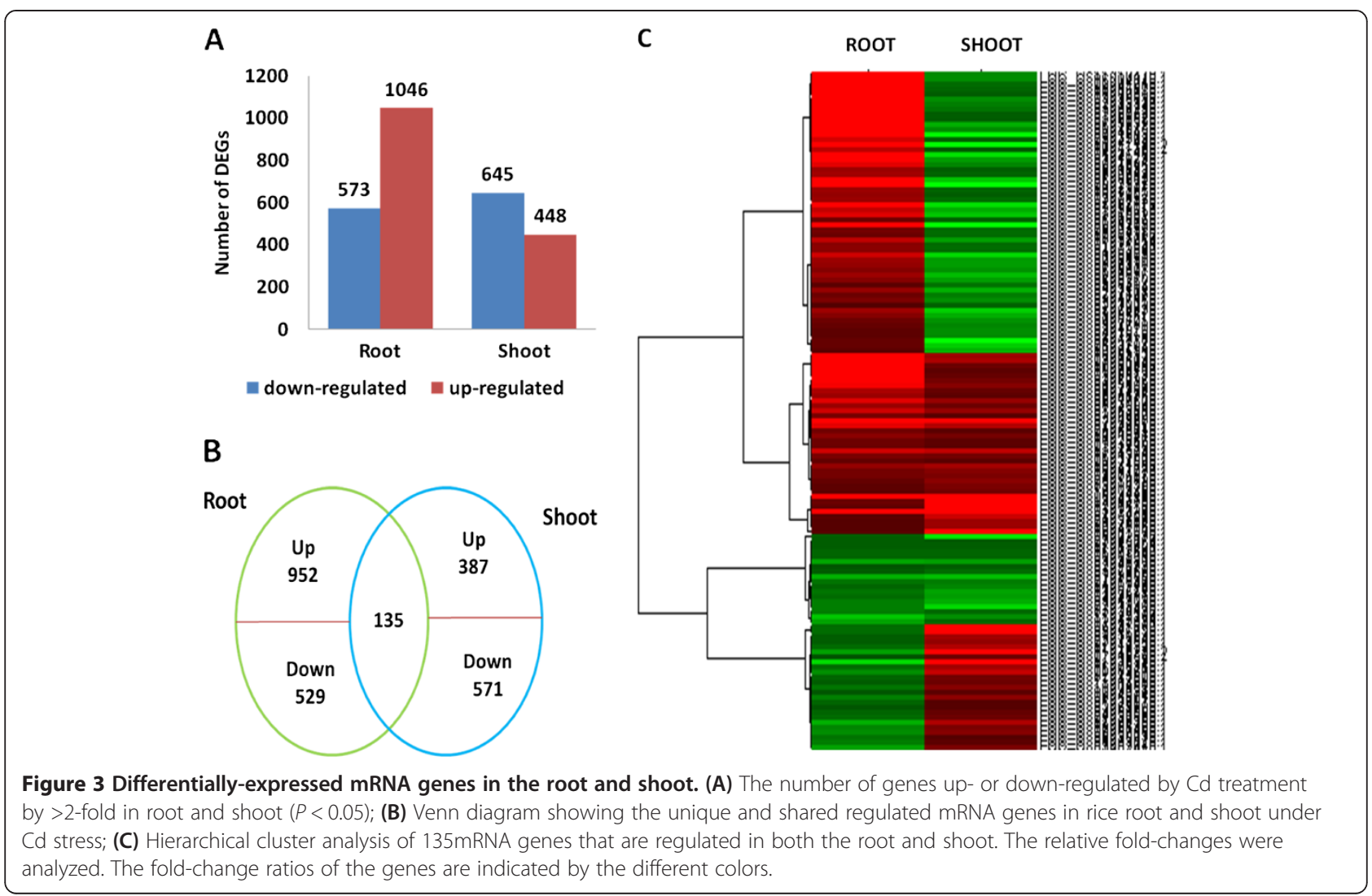

and intracellular organelles were most significant among the cellular component GO terms in the shoot (Figure 4B), while there were no significant cellular component GO terms in the root (Figure 4A).

In an effort to obtain more biological information regarding the molecular and biochemical responses that occur in rice seedlings exposed to Cd treatment, we integrated the $\mathrm{Cd}$-responsive genes set with processes in the KEGG pathway. By applying a cut-off criterion of Q-value $<0.05$, the enrichment analysis revealed a few important pathways that were significantly enriched in response to $\mathrm{Cd}$ stress (Table 3). It was quite evident that, genes involved in certain kinds of secondary metabolite synthesis, such as phenylpropanoids, glutathione, phenylalanine, isoflavonoids, diterpenoids, galactose, carotenoids, amino sugars, and nucleotide sugars, were significantly enriched in the root. We also found that genes for plant hormone signal transduction, protein processing in the endoplasmic reticulum, and $\mathrm{ABC}$ transporters were enriched in the root. However, only two pathways, those for ribosome biogenesis and carotenoid biosynthesis, were significantly enriched in the shoot (Table 3 ). These results indicated that the main responses to $\mathrm{Cd}$ stress occurred in the root, and only a few changes, protein and carotenoid biosynthesis, took place in the shoot. The most significantly enriched pathway was plant hormone signal transduction in the root, with 94 genes differentially expressed between the $\mathrm{Cd}$ treatment and the control.

The hormone-related pathway included auxin, salicylic acid (SA), brassinosteroids (BRs), ethylene (ET), GAs, jasmonate acid (JA) and abscisic acid (ABA) signaling pathway(Additional file 11: Table S7). Most obviously, five PR1 genes and six JAZ genes were up-regulated indicating that the SA and JA signaling pathways were activated. In the BR signaling pathway, six BAK1 and seven BRI1 genes were up-regulated and other five BRI1 genes were down-regulated. Except for three CTR1 genes in ET signaling pathway were downregulated, another six ERF genes were up-regulated. In the GA signaling pathway, eight GID1 genes were upregulated and three GID1 genes were down-regulated, four DELLA protein genes up-regulated and one downregulated. Four SAU1 genes in auxin signaling pathway were up-regulated and two SAU1 genes were down regulated. In addition, we found six PP2C genes and one $\mathrm{ABF}$ gene were heavily up-regulated in ABA signaling pathway.

\section{Combined expression analysis of microRNAs and their target mRNAs during $\mathrm{Cd}$ treatment}

In our further analysis, we focus on the trend of expression changes of miRNA and its target genes. If a target 

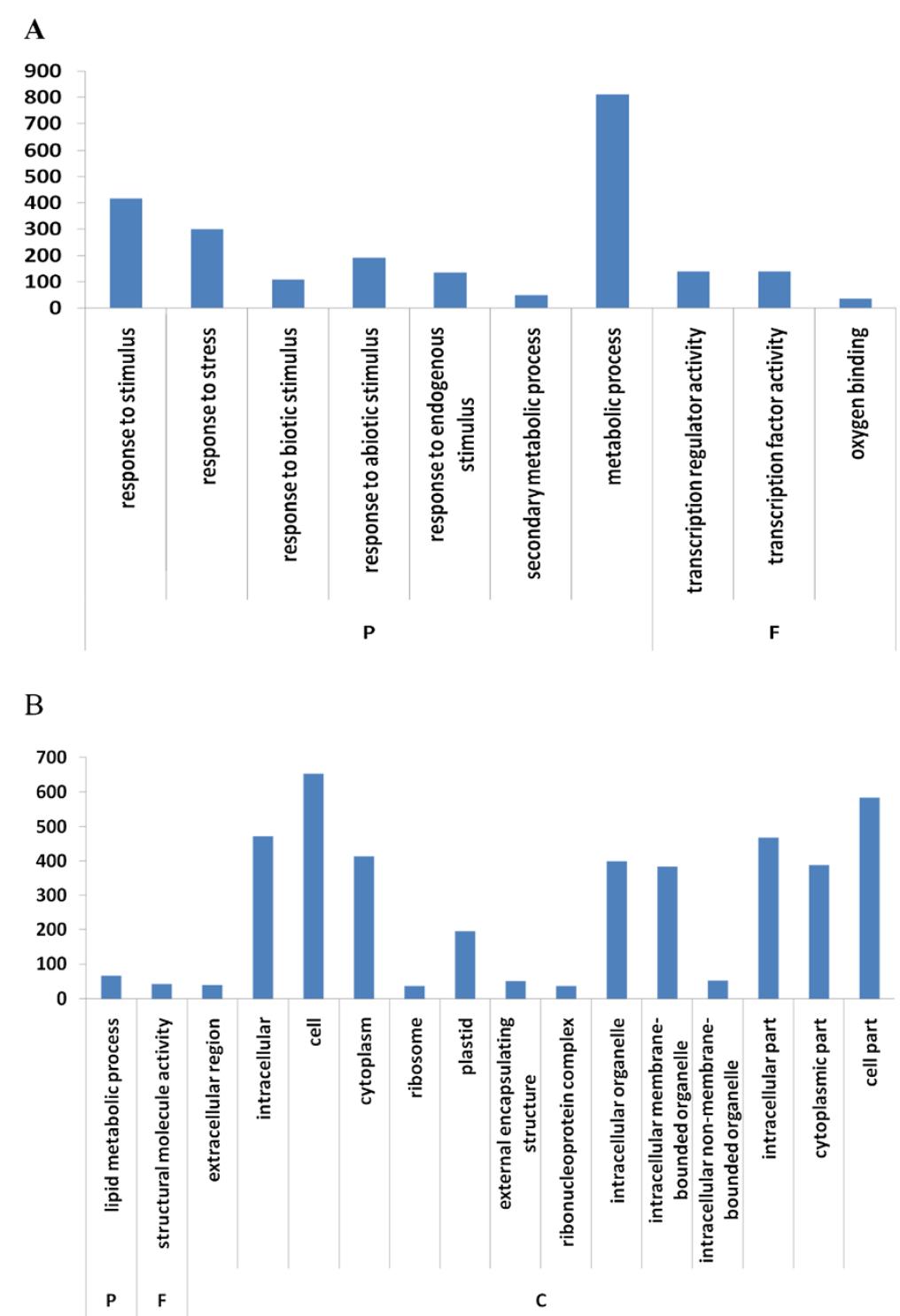

Figure 4 Gene Ontology (GO) analysis. biological process (P), molecular function (F), and cellular component (C)-of differentially-expressed genes in root $(\mathbf{A})$ and shoot $(\mathbf{B})$ in response to $C d$ stress $(P<0.05)$. The $y$-axis and $x$-axis indicate the number of genes in a category and the names of the clusters, respectively.

gene is down-regulated, it suggests that the effective activity of this miRNA is enhanced under the treatment. Vice versa, an up-regulation of a target gene indicates a decrease activity of the corresponding miRNA. Therefore, a miRNA-mRNA interaction pair means antiregulation of a miRNA and a corresponding mRNA $[41,42]$. In order to identify correlations between them, we searched two online databases to find predicted targets in the plant microRNA database (PMRD) (http://bioinformatics.cau.edu.cn/PMRD/) [43] and starBase (http://starbase.sysu.edu.cn/) [44]. There were 9,053 miRNA-mRNA pairs in PMRD, and 2,927 pairs in starBase v2.0, with 1,801 pairs common to the two databases.
This large difference in the numbers was due to the fact that most of pairs in starBase were identified based on CLIP-Seq and Degragome-Seq data, while miRNA-mRNA pairs in PMRD were mainly predicted computationally. In order to acquire high quality, complete information regarding miRNA and mRNA expression, we integrated our sequencing data into these two databases.

In our miRNA sequencing results, we acquired a total of 141 differentially-expressed miRNAs belonging to 48 different families in the root (Additional file 6: Table S3), and 39 miRNAs belonging to 23 families in the shoot (Additional file 7: Table S4). Based on the two downloaded 
Table 3 Significant pathways and proportions after KEGG (Kyoto Encyclopedia of Genes and Genomes) analysis of differentially expressed genes in the root and shoot $(Q \leq 0.05)$

\begin{tabular}{|c|c|c|c|c|c|c|}
\hline Number & Pathway & $\begin{array}{l}\text { DEGs with pathway } \\
\text { annotation (866) }\end{array}$ & $\begin{array}{l}\text { All genes with pathway } \\
\text { annotation }(28280)\end{array}$ & P-value & Q-value & Pathway ID \\
\hline $\mathrm{R}-1$ & Plant hormone signal transduction & $94(10.85 \%)$ & $1560(5.52 \%)$ & $2.84 \mathrm{E}-10$ & $3.15 \mathrm{E}-08$ & ko04075 \\
\hline $\mathrm{R}-2$ & Phenylpropanoid biosynthesis & $48(5.54 \%)$ & $596(2.11 \%)$ & 1.43E-09 & 7.93E-08 & ko00940 \\
\hline $\mathrm{R}-3$ & Glutathione metabolism & $23(2.66 \%)$ & $193(0.68 \%)$ & $3.02 \mathrm{E}-08$ & $1.12 \mathrm{E}-06$ & ko00480 \\
\hline $\mathrm{R}-4$ & Phenylalanine metabolism & $27(3.12 \%)$ & $279(0.99 \%)$ & $1.60 \mathrm{E}-07$ & 4.45E-06 & ko00360 \\
\hline R-5 & $\begin{array}{l}\text { Stilbenoid, diarylheptanoid and gingerol } \\
\text { biosynthesis }\end{array}$ & $28(3.23 \%)$ & $346(1.22 \%)$ & $3.46 \mathrm{E}-06$ & 7.69E-05 & ko00945 \\
\hline R-6 & Isoflavonoid biosynthesis & $16(1.85 \%)$ & $139(0.49 \%)$ & 5.89E-06 & 1.09E-04 & ko00943 \\
\hline $\mathrm{R}-7$ & Limonene and pinene degradation & $21(2.42 \%)$ & $228(0.81 \%)$ & 8.07E-06 & $1.28 \mathrm{E}-04$ & ko00903 \\
\hline $\mathrm{R}-8$ & Protein processing in endoplasmic reticulum & $39(4.5 \%)$ & $614(2.17 \%)$ & $1.70 \mathrm{E}-05$ & $2.24 \mathrm{E}-04$ & ko04141 \\
\hline R-9 & Diterpenoid biosynthesis & $20(2.31 \%)$ & $222(0.79 \%)$ & $1.82 \mathrm{E}-05$ & $2.24 \mathrm{E}-04$ & ko00904 \\
\hline $\mathrm{R}-10$ & $A B C$ transporters & $20(2.31 \%)$ & $255(0.9 \%)$ & 0.000127 & $1.42 \mathrm{E}-03$ & ko02010 \\
\hline $\mathrm{R}-11$ & Flavonoid biosynthesis & $23(2.66 \%)$ & $351(1.24 \%)$ & 0.00057 & $5.75 \mathrm{E}-03$ & ko00941 \\
\hline $\mathrm{R}-12$ & Brassinosteroid biosynthesis & $9(1.04 \%)$ & $81(0.29 \%)$ & 0.000826 & 7.64E-03 & ko00905 \\
\hline $\mathrm{R}-13$ & Galactose metabolism & $13(1.5 \%)$ & $155(0.55 \%)$ & 0.001002 & $8.56 \mathrm{E}-03$ & ko00052 \\
\hline R-14 & Biosynthesis of secondary metabolites & $166(19.17 \%)$ & $4372(15.46 \%)$ & 0.001623 & $1.29 \mathrm{E}-02$ & ko01110 \\
\hline $\mathrm{R}-15$ & alpha-Linolenic acid metabolism & $13(1.5 \%)$ & $170(0.6 \%)$ & 0.002303 & $1.70 \mathrm{E}-02$ & ko00592 \\
\hline $\mathrm{R}-16$ & Alanine, aspartate and glutamate metabolism & $10(1.15 \%)$ & $118(0.42 \%)$ & 0.003429 & $2.34 \mathrm{E}-02$ & ko00250 \\
\hline $\mathrm{R}-17$ & $\begin{array}{l}\text { Glycosylphosphatidylinositol(GPI)-anchor } \\
\text { biosynthesis }\end{array}$ & $14(1.62 \%)$ & $200(0.71 \%)$ & 0.003586 & $2.34 \mathrm{E}-02$ & ko00563 \\
\hline $\mathrm{R}-18$ & Carotenoid biosynthesis & $18(2.08 \%)$ & $294(1.04 \%)$ & 0.004432 & 2.73E-02 & ko00906 \\
\hline $\mathrm{R}-19$ & Amino sugar and nucleotide sugar metabolism & $19(2.19 \%)$ & $329(1.16 \%)$ & 0.006526563 & $3.81 \mathrm{E}-02$ & ko00520 \\
\hline S-1 & Ribosome & $35(5.46 \%)$ & $542(1.92 \%)$ & $3.69 \mathrm{E}-08$ & $3.80 \mathrm{E}-06$ & ko03010 \\
\hline $\mathrm{S}-2$ & Carotenoid biosynthesis & $17(2.65 \%)$ & $294(1.04 \%)$ & 0.000435344 & $2.24 \mathrm{E}-02$ & ko00906 \\
\hline
\end{tabular}

data sets, we first searched the expression of all different miRNA targets. We then filtered possible targets based on a pre-determined cut-off point $(\mid \log 2$ Ratio $\mid \geq 1$ and FDR $<0.001$ ). As a result, we independently acquired 13 miRNA-mRNA pairs from starBase and 30 pairs from PMRD (Additional file 12: Table S8). A Venn diagram showed that 10 of the microRNA-mRNA interaction pairs were acquired from both of the databases (Table 4). One target (LOC_Os09g15420.1) of miR1433 was up-regulated by miRNAs during $\mathrm{Cd}$ treatment (Figure $5 \mathrm{~A}$ ), and it is a putative NAD-dependent epimerase/dehydratase family protein. Two targets of miR1436 were also up-regulated in response to $\mathrm{Cd}$ treatment (Figure $5 \mathrm{~B}$ ); these were LOC_Os09g34250.1 and LOC_Os05g50570.1, of which LOC_Os09g34250.1 is a predicted UDP-glucoronosyl and UDP-glucosyl transferase domain-containing protein, and LOC_Os05g50570.1 is a putative serine carboxypeptidase homologue. Two targets (LOC_Os04g38720.1 and LOC_Os12g05260.1) of miR164a/b/f and miR164d were also up-regulated in the pairs (Figure 5C). Because miR164a, miR164b, and miR164f share the same sequence, deep sequencing cannot distinguish them, and we thus denoted them as miR164a/b/f (Figure 5C). These two targets are a putative phytosulfokine precursor and NAC (NAM/ATAF1/CUC2) protein, respectively. Although we identified 39 differentially-expressed miRNAs and 1,093 mRNAs in the shoot, no interaction pairs were identified in the above two databases.

In addition to analyzing the interactions between known miRNAs and mRNAs, we also investigated new miRNA-mRNA interaction pairs in response to $\mathrm{Cd}$ stress. Firstly, we predicted new miRNA candidates' targets (Additional file 13: Table S9) by using a plant target prediction tool available in the University of East Anglia (UEA) sRNA toolkit (http://srna-workbench.cmp.uea.ac.uk/) [34]. After integrating the predicted targets with our sequencing data, we then acquired six miRNA-mRNA interaction pairs showing opposing expression patterns from the root (Table 5 and Additional file 9: Table S6). Five predicted targets (LOC_Os01g50310.1, LOC_Os02g32620.1, LOC_Os04g35800.1, LOC_Os01g52260.1 and LOC_ Os06g18140.1) of miRR2 were up-regulated under $\mathrm{Cd}$ stress (Figure 6A). These five targets were a putative VIP1 protein, a PAN domain-containing protein, a 
Table 4 mRNA targets predicted in common from two databases for differentially expressed miRNAs in root

\begin{tabular}{|c|c|c|c|c|c|c|c|}
\hline \multirow{2}{*}{$\begin{array}{l}\text { miRNA } \\
\text { Family }\end{array}$} & \multirow{2}{*}{$\begin{array}{l}\text { miRNA } \\
\text { Name }\end{array}$} & \multirow{2}{*}{$\begin{array}{l}\text { Target Gene- } \\
\text { Interaction }\end{array}$} & \multicolumn{2}{|c|}{ miRNA expression level } & \multicolumn{2}{|c|}{ mRNA expression level } & \multirow[b]{2}{*}{ Targets annotation } \\
\hline & & & $\begin{array}{l}\text { CR/KR-Fold } \\
\text { change }\end{array}$ & P-value & $\begin{array}{l}\text { CR/KR-Fold } \\
\text { change }\end{array}$ & P-value & \\
\hline osa-miR1433 & osa-miR1433 & 09 g15420.1 & -2.41 & 0.00 & 1.33 & 0.00 & $\begin{array}{l}\text { NAD dependent epimerase/dehydratase } \\
\text { family protein }\end{array}$ \\
\hline \multirow{2}{*}{ osa-miR1436 } & osa-miR1436 & 09 g34250.1 & -2.15 & 0.00 & 1.73 & 0.00 & $\begin{array}{l}\text { UDP-glucoronosyl and UDP-glucosyl } \\
\text { transferase domain containing protein }\end{array}$ \\
\hline & osa-miR1436 & 05 g50570.1 & -2.15 & 0.00 & 11.00 & 0.00 & $\begin{array}{l}\text { OsSCP29 - Putative Serine } \\
\text { Carboxypeptidase homologue }\end{array}$ \\
\hline \multirow{7}{*}{ osa-miR164a } & osa-miR164a & $12 \mathrm{~g} 05260.1$ & -1.36 & 0.00 & 1.07 & 0.00 & phytosulfokines precursor \\
\hline & osa-miR164a & 04 g38720.1 & -1.36 & 0.00 & 1.29 & 0.00 & no apical meristem protein \\
\hline & osa-miR164b & $12 \mathrm{~g} 05260.1$ & -1.36 & 0.00 & 1.07 & 0.00 & phytosulfokines precursor \\
\hline & osa-miR164b & 04 g38720.1 & -1.36 & 0.00 & 1.29 & 0.00 & no apical meristem protein \\
\hline & osa-miR164f & 12 g05260.1 & -1.36 & 0.00 & 1.07 & 0.00 & phytosulfokines precursor \\
\hline & osa-miR164f & 04 g38720.1 & -1.36 & 0.00 & 1.29 & 0.00 & no apical meristem protein \\
\hline & osa-miR164e & $04 \mathrm{~g} 38720.1$ & -1.35 & 0.00 & 1.29 & 0.00 & no apical meristem protein \\
\hline
\end{tabular}

zinc-finger family protein, a serine acetyltransferase protein, and a UDP-glucoronosyl and UDP-glucosyl transferase domain-containing protein, respectively. Besides, a ribosome-inactivating protein (LOC_Os01g06740.1), a target of miRR3, was also regulated under $\mathrm{Cd}$ stress (Figure 6B).
Biological repeatability analysis,real-time RT-PCR validation and metabolite changes verification

To validate our results, we ran biological repeatability analyses based on two independent Cd treatment libraries which were also constructed from root tissue treated with $\mathrm{CdCl}_{2}$ for six hours. Scatter plots of TPM (number
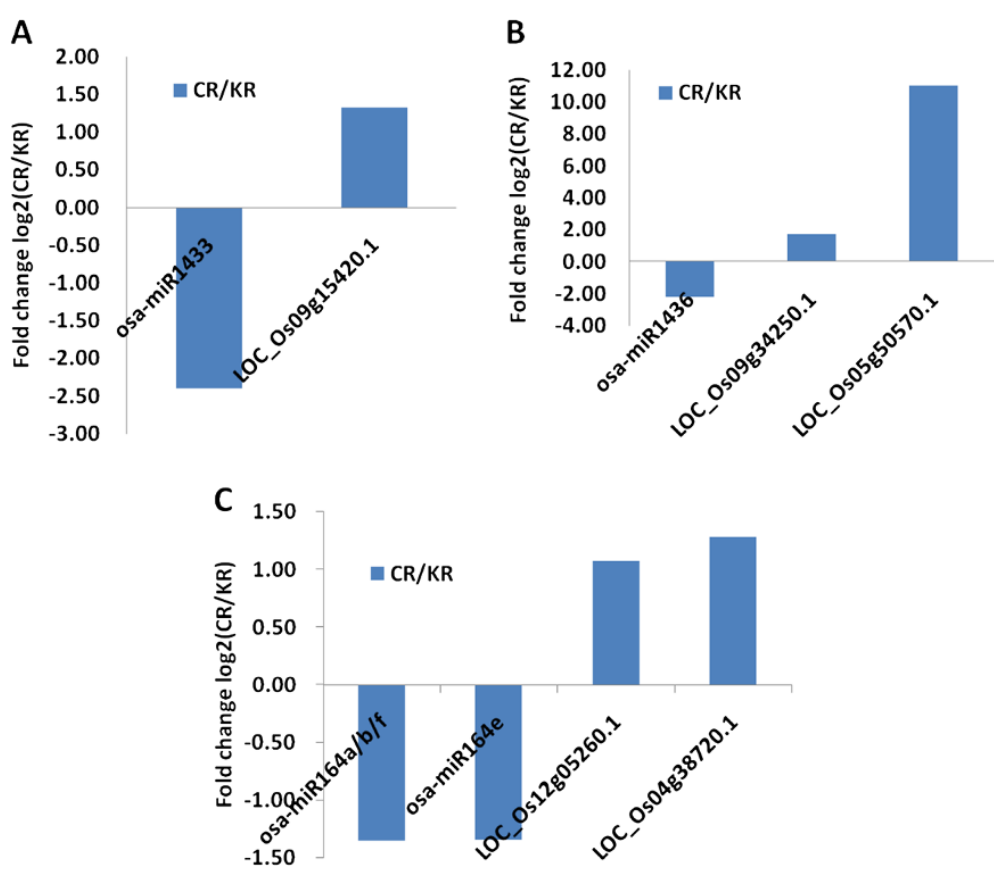

Figure 5 Representative correlations between miRNAs and mRNAs from two datasets. Results shown are the fold changes in expression of these transcripts in Cd-treated roots compared to the control. (A) The opposite expression pattern of osa-miR1433 and its target LOC_Os09g15420.1; (B) The opposite expression pattern of osa-miR1436 and its targets LOC_Os09g34250.1 and LOC_Os05g50570.1; (C) The opposite expression pattern of osa-miR164a/b/f, osa-miR164e and their targets LOC_Os12g05260.1 and LOC_Os04g38720.1. 
Table 5 Interaction pairs for new miRNA candidates and predicted mRNA targets in root

\begin{tabular}{|c|c|c|c|c|c|c|c|}
\hline \multirow[b]{2}{*}{$\begin{array}{l}\text { SRNA } \\
\text { ID }\end{array}$} & \multirow[b]{2}{*}{$\begin{array}{l}\text { Start-end position } \\
\text { of target }\end{array}$} & \multirow[b]{2}{*}{$\begin{array}{l}\text { Target gene } \\
\text { accession }\end{array}$} & \multicolumn{2}{|c|}{ miRNA expression level } & \multicolumn{2}{|c|}{ mRNA expression level } & \multirow[b]{2}{*}{ Targets annotation } \\
\hline & & & $\begin{array}{l}\text { CR/KR-Fold } \\
\text { change }\end{array}$ & P-value & $\begin{array}{l}\text { CR/KR-Fold } \\
\text { change }\end{array}$ & P-value & \\
\hline miRR2 & 19-39 & 01 g50310.1 & -1.39 & 0.01 & 1.67 & 0.00 & VIP1 protein \\
\hline miRR2 & $339-357$ & $02 \mathrm{~g} 32620.1$ & -1.39 & 0.01 & 1.90 & 0.00 & PAN domain-containing protein At5g03700 precursor \\
\hline miRR2 & $95-114$ & $04 \mathrm{~g} 35800.1$ & -1.39 & 0.01 & 2.49 & 0.00 & zinc finger $\mathrm{C}-\mathrm{x} 8-\mathrm{C}-\mathrm{x} 5-\mathrm{C}-\mathrm{x} 3-\mathrm{H}$ type family protein \\
\hline miRR2 & $522-540$ & 01 g52260.1 & -1.39 & 0.01 & 3.06 & 0.00 & serine acetyltransferase protein \\
\hline miRR2 & $107-126$ & 06 g18140.1 & -1.39 & 0.01 & 3.84 & 0.00 & $\begin{array}{l}\text { UDP-glucoronosyl and UDP-glucosyl transferase } \\
\text { domain containing protein }\end{array}$ \\
\hline miRR3 & $414-432$ & 01 g06740.1 & -1.13 & 0.01 & 7.05 & 0.00 & ribosome inactivating protein \\
\hline
\end{tabular}

of transcripts per million clean tags) from the two independent libraries were constructed to explore their relativity, with Pearson correlation values of $\mathrm{r}=0.98$ (Figure 7A). Eighty-three of 141 differentially-expressed miRNAs were found to have changes in relative expression levels in our second miRNA library; 1,124 of 1,616 differentially-expressed mRNAs were found to be changed in the mRNA library, and six out of 10 miRNAmRNA interaction pairs were simultaneously identified. These results showed the representation of every library in our analysis.

To validate the expression data further, the relative expression levels of selected genes were investigated with qRT-PCR. We first randomly choose 20 differentiallyexpressed mRNAs and 10 miRNAs from our sequencing data, and specific primers were used to quantify each gene (Additional file 1: Figure S2; Additional file 2: Table S10). At least three biological replicates and three technical replicates were performed to ensure the quantification of each gene. Correlation between the relative expression level detected by qRT-PCR and by deepsequencing was calculated. Pearson correlation values were highly significant with $r=0.95$ (Figure 7B), which strongly supported the sequencing data. Then, we validated 41 key $\mathrm{Cd}$-responsive genes including transcription factors, kinase, metabolic enzymes and transporters (Additional file 2: Table S10). A similar result was observed with the validation of the key Cd-responsive genes as shown in Additional file 2: Table S10; most of them have the same expression pattern with the sequencing data and confirmed the differences in gene expression patterns during $\mathrm{Cd}$ stress.

Based on our transcriptome data, we can conclude that carotenoid biosynthesis was affected in the shoot under $\mathrm{Cd}$ stress. To verify the transcriptome result metabolically, we measured the change in ABA content, which is a direct down-stream product of carotenoid metabolism, using an HPLC system. The ABA content in the control was $0.60 \pm 0.06 \mu \mathrm{g} / \mathrm{g}$ dry weight. After $6 \mathrm{~h}$ of $\mathrm{Cd}$ stress, when tissue for our expression data was harvested, the $\mathrm{ABA}$ content rose to $0.81 \pm 0.10 \mu \mathrm{g} / \mathrm{g}$ dry weights. There was a $34.30 \%$ increase in ABA content in comparison with the control $(\mathrm{P} \leq 0.01)$ (Additional file 14: Figure S3). This result independently supports our expression data showing that carotenoid biosynthesis was affected in the early stage of $\mathrm{Cd}$ stress in shoots.
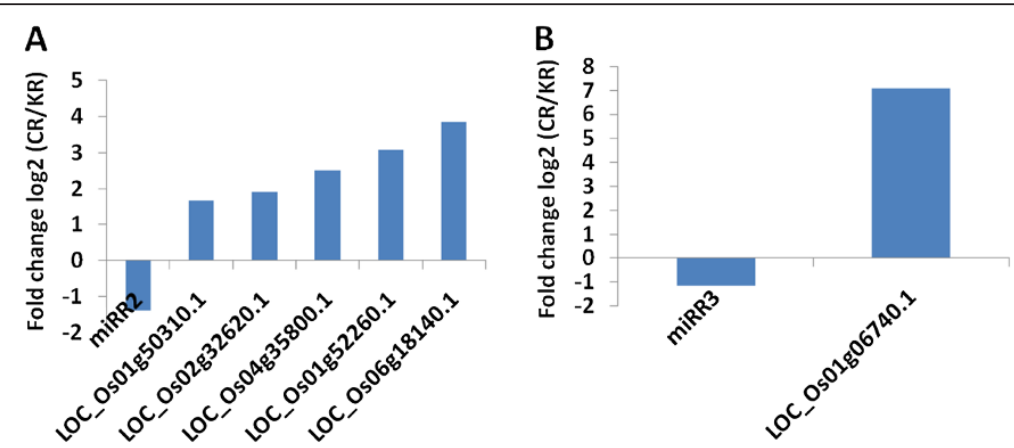

Figure 6 Representative correlations between new miRNA candidates and predicted mRNA targets. Results shown are the fold changes in expression of these transcripts in Cd-treated roots compared to the control. (A) The opposite expression pattern of miRR2 and its targets LOC_Os01g50310.1, LOC_Os02g32620.1, LOC_Os04g35800.1, LOC_Os01g52260.1 and LOC_Os06g18140.1; (B) The opposite expression pattern of miRR3 and its target LOC_Os01g06740.1. 

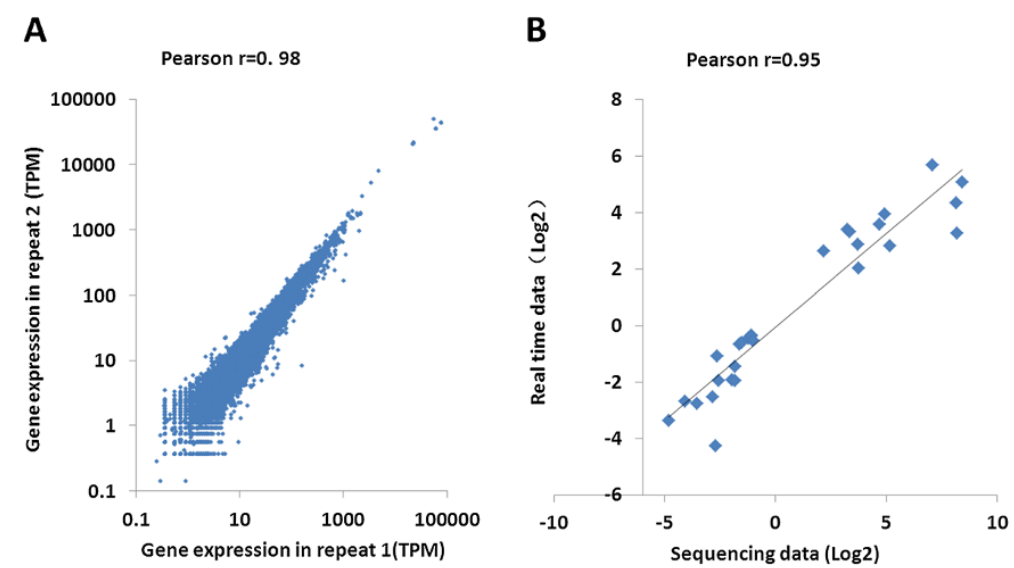

Figure 7 Correlation of gene expression ratios between the two replicates (A), and between sequencing data and quantitative RT-PCR data (B). (A) Reproducibility analysis of two independent libraries constructed from root tissue treated with $\mathrm{CdCl}_{2}$ for 6 hours. The relativity analysis was based on the TPM from these two libraries. (B) Pearson correlation scatters plots of comparisons of ratios measured by sequencing and quantitative RT-PCR in mRNAs and miRNAs. Thirty genes, including 20 mRNAs and 10 miRNAs, were randomly selected and were subjected to quantitative real-time PCR analysis. The rice UBC and U6 RNAs were used as internal standards. Sequencing data (fold changes in gene expression) were plotted against qRT-PCR data (fold-changes in gene expression). Both the $x$ and $y$-axes are shown in $\log _{2}$ scale. $r$ indicates the Pearson correlation coefficient.

\section{Discussion}

The high-throughput sequencing method has become a powerful tool to analyze the expression profiles of genes and identify low-abundance novel miRNAs $[24,45]$. Global expression profiling analysis of miRNAs and mRNAs in the same samples may provide a unique opportunity to enhance our understanding of potential miRNA regulatory mechanisms in rice seedlings exposed to Cd. In this study, a total of 146 differentially-expressed miRNAs were identified in the root and 39 in the shoot (Additional file 6: Table S3 and Additional file 7: Table S4). Also, 137, 69, 154, and 165 new miRNA candidates were identified in the KR, CR, KS, and CS libraries, respectively (Additional file 8: Tables S5). The number of differentially-expressed new miRNA candidates was eight in the root and five in the shoot. Previous studies using microarray technology or qRT-PCR to investigate transcriptional regulation of the plant response to Cd stress also identified some differentially-expressed miRNAs. In rice, a total of 19 Cd-responsive miRNAs were identified in Cd-treated rice based on a microarray assay [13]. Ten miRNAs including miR162a, miR168a, miR166e, miR171a, miR171b, miR171g, miR156a, miR156k, miR156l, and miR444b.1 were identified as having the same expression pattern in our study (Additional file 6: Table S3). A previous sequencing study identified 19 novel Cd stress-regulated miRNAs and nine known miRNAs from miRBase in a library of small RNAs from Cd-treated rice seedlings [14]. Six known miRNAs including miR160, miR164, miR167, miR168, miR169, and miR171 were also identified in our study. These limiting but important references show that numerous miRNAs are involved in the Cd stress-response in rice. In M. truncatula, miR393, miR171, miR319, and miR529 were up-regulated, whereas miR166 and miR398 were downregulated in response to $\mathrm{Cd}$ treatment as determined by a qRT-PCR-based assay [16]. Compared with these studies, which were limited to known miRNAs, our direct sequencing data detected both known and new miRNA candidates, and thus provided a more comprehensive result.

Under Cd stress, plants respond with several physiological changes:(1) excluding $\mathrm{Cd}$ from root absorption by excreting organic acids such as malate or citrate to chelate and immobilize $\mathrm{Cd}$ in the soil matrix [46], (2) immobilizing $\mathrm{Cd}$ and preventing its uptake into the cytosol by cell wall and extracellular carbohydrates [47], and (3) producing chelating compounds such as phytochelatins or metallothioneins to detoxify and localize $\mathrm{Cd}$ to specific cellular compartments [48]. Certainly, plants will produce stress-related proteins and signaling molecules, which will affect plant hormone levels and signal transduction [47]. A simple model was constructed on the basis of our transcriptome data along with the physiological changes under Cd stress (Figure 8). Under $\mathrm{Cd}$ stress, different responses occurred in the root and shoot. In the root, the antioxidant system, phosphorylation cascade, plant hormone signaling and detoxification and protection system were activated. In the shoot, the most significant change was the down-regulation of the ribosome protein expression levels and carotenoid biosynthesis.

In our DEG data, we found that synthesis of secondary metabolites such as glutathione, phenylpropanoids, 


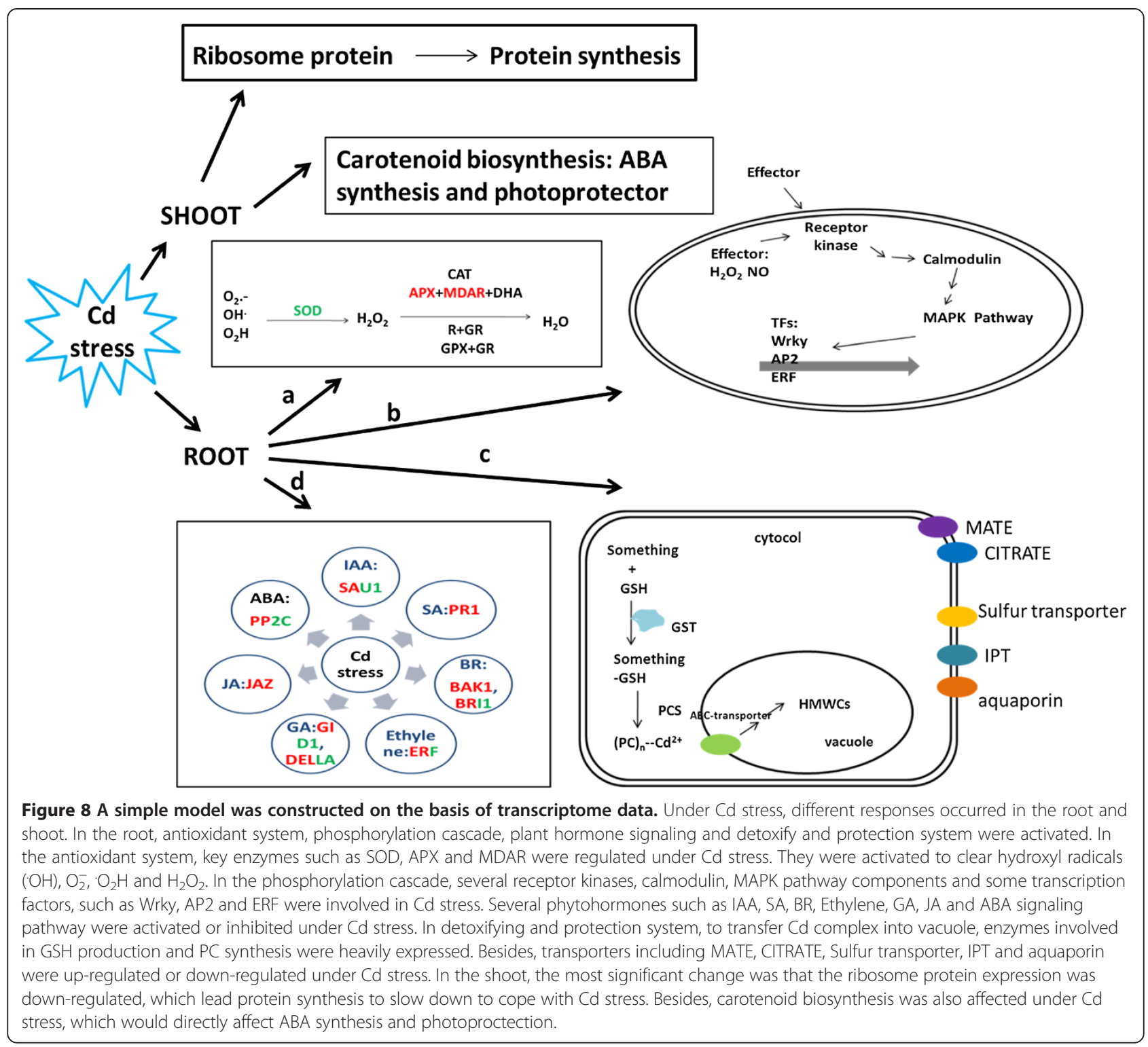

stilbenoids, diarylheptanoids, gingerol, and flavonoids, signaling molecules and $A B C$ transporters were significantly altered by Cd stress (Table 3 ). This is consistent with previous results that identified genes involved in sulfur assimilation-reduction, glutathione (GSH) metabolism, enzymes catalyzing the biosynthesis of phenylpropanoids, unfolded protein binding, antioxidant responses, and metal transport [17,23,49-51]. Based on a fluorescent differential display method, sequences related to signal transduction, protein denaturing stress, and responses to signal transduction were found to be controlled by Cd-responsive genes in A. thaliana [51]. Some signaling molecules including transcription factors such as DREB1 (Dehydration-Responsive Element Binding protein) and NAC (NAM, ATAF1/2 and CUC2 domain proteins), and protein kinases were induced in response to Cd stress [23]. In addition, Cd-regulated PDR (plant pleiotropic drug resistance) and MATE (Multidrug and toxic compound extrusion) family transporter genes were strongly up-regulated [23].

The ribosomal proteins are highly conserved components of ribosomal subunits involved in the cellular process of translation [52]. A proteomic study found that ribosome proteins were induced in response to early $\mathrm{Cd}$ stress, while repressed under long time stress in Schizosaccharomyces pombe [53]. Similarly, we found most ribosomal proteins were down-regulated in our study, indicating that the protein synthesis process was decreased heavily under $\mathrm{Cd}$ stress. In fact, the regulation of ribosome biogenesis is required to save energy and 
nutrients, and to adapt to environment changes [54]. Under Cd stress, reduction in the synthesis of ribosomal proteins is necessary to permit energy and other resources to be distributed to other processes involved in surviving.

In this study, we found that the expression of several key genes in carotenoids synthesis were induced or decreased under $\mathrm{Cd}$ stress in both root and shoot. Carotenoids represent the second most abundant pigments in nature. They harvest light for photosynthesis and act as photoprotectors for plant adaptation to high intensity light stress [55]. Previous studies shown that exposure to $\mathrm{Cd}$ stress will lead to impairment of the photosynthetic function in many plant species. Both chlorophylls and carotenoid contents decrease under $\mathrm{Cd}$ exposure $[48,56,57]$. In our study, ABA content was increased and its signaling pathway was activated. Oxidative cleavage of carotenoids will produce apocarotenoids, while the phytohormone $\mathrm{ABA}$ is an apocarotenoid derivative [58]. ABA was found taking part in the regulation of antioxidative defense systems and $\mathrm{Cd}$-induced oxidative stress in mung bean seedlings [59]. All these results suggest that both the synthesis of carotenoids and the ABA signaling pathway were conservatively involved in the plant $\mathrm{Cd}$ stress response.

Previous studies have shown that plants can activate the expression of antioxidant enzymes against the occurrence of activated oxygen and oxidative injury caused by Cd stress [17-19], and these biological processes were also observed in our analysis (Table 3; Figure 8). Importantly, these activities may be directly associated with tolerance to stress. For example, rice Xiushui 110, which is highly tolerant to $\mathrm{Cd}$ toxicity, had the greatest increase in SOD and POD activities. In contrast, rice variety Bing 9914, which is sensitivity to Cd toxicity, had the least increase in activities of antioxidative enzymes [60]. Therefore, investigating the $\mathrm{Cd}$ response activity has great significance to understand the plant tolerance mechanism and may benefit the selection of plant varieties for phytoremediation.

In general, increased miRNA activity will lead to the down-regulation of an mRNA target, while decreased miRNA activity will lead to up-regulation of the target. Though miRNAs regulate target gene expression by repressing their targets through transcript cleavage or translation repression $[4,61,62]$, integrated analysis of miRNA and mRNA expression profiles can still be helpful to identify the functional miRNA-mRNA interaction pairs involved in regulating specific biological processes [63]. After integrated analysis of differentially expressed miRNAs and mRNAs, we found several important regulatory miRNAs involved in Cd stress. MiR1433 appeared to target NAD-dependent epimerase/dehydratase family proteins in response to $\mathrm{Cd}$ treatment (Figure 5A). Previous studies showed that this family of proteins utilizes NAD as a cofactor to take part in a variety of chemical reactions [64], suggesting that various metabolic changes occur during $\mathrm{Cd}$ stress, and the down-regulation of miRNAs leads to the rapid production of this kind of protein to catalyze different metabolic processes. MiR1436 targets UDP-glucoronosyl and UDP-glucosyl transferase domain-containing proteins and a putative serine carboxypeptidase homologue (Figure 5B). Combined with the NAD-dependentepimerase/dehydratase family protein, we can conclude that the most significant changes in response to $\mathrm{Cd}$ stress were metabolic processes. Other than metabolic changes, a NAC family transcription factor, a target of miR164, was also up-regulated due to $\mathrm{Cd}$ treatment (Figure 5C). One new miRNAs, miRR2, appeared to target one zinc-finger family protein (Table 5 and Figure 6). Previous results have shown that numerous transcription factors are involved in the $\mathrm{Cd}$ response $[65,66]$. Five miRNA families (miR166, miR171, miR396, miR156, and miR444), whose target genes encode transcription factors, were all down-regulated in response to $\mathrm{Cd}$ exposure in rice [13].

In this study, we detected 146 miRNAs that showed differential expression in response to $\mathrm{Cd}$ stress in the root and 39 in the shoot. However, only six miRNAs were identified that form a total of 10 miRNA-mRNA interaction pairs. This number is far below our expectation that more interaction pairs would be found from the 146 miRNAs. Possible reasons to explain this phenomenon include: (1) the commonly-predicted targets in the two online databases do not represent the actual existing interactions, (2) plants can regulate the expression of specific genes at the temporal and spatial levels, and most targets may not be expressed at this point, and (3) the accepted standard used for the definition of differentially-expressed genes may miss some interactions, and more interaction pairs may be identified by lowering the threshold. We found that there were no interaction pairs in the shoot, and the responsive miRNAs and mRNAs were fewer than in root, especially the number of miRNAs. A time-course analysis of gene regulation under $\mathrm{Cd}$ stress in rice found that, compared with the root, the shoot had fewer Cd-responsive genes when exposed to $1 \mu \mathrm{M} \mathrm{Cd}$ for 24-72 $\mathrm{h}$ [23], which supports our results. When the exposure time was extended to eight days, the number of Cd-regulated genes in shoots was larger than it was in roots. Therefore, the treatment time and concentration may explain the differential gene expression patterns seen in the root and the shoot.

\section{Conclusions}

Four libraries were constructed, amplified and sequenced with root and shoot tissues from 7-day-old rice seedlings exposed to solutions with and without $60 \mu \mathrm{M} \mathrm{CdCl}_{2}$ for 
6 h. 141 known miRNAs belonging to 48 families and 39 known miRNAs in 23 families were identified to be differentially expressed in the root and the shoot, respectively. In addition, we identified eight new miRNA candidates from the root and five from the shoot that were differentially expressed in response to $\mathrm{Cd}$ treatment. For the mRNAs, we identified 1,044 genes in the root and 448 genes in the shoot that were up-regulated, while 572 and 645 genes were down-regulated in the root and shoot, respectively. GO and KEGG enrichment analyses showed that genes encoding secondary metabolite synthases, signaling molecules, and $\mathrm{ABC}$ transporters were significantly enriched in the root, while ribosomal protein and carotenoid biosynthesis genes were significantly enriched in the shoot. We identified 10 known and six new miRNA-mRNA interaction candidate pairs that showed significant inverse expression patterns. This work provides an important advance in the functional identification of miRNAs and how they interact with their targets in response to $\mathrm{Cd}$ treatment. Studies on each interaction pair will provide more fundamental information about how plants respond to $\mathrm{Cd}$ stress at the molecular level.

\section{Availability of supporting data}

The raw reads reported in this study have been deposited in the National Center for Biotechnology Information Short Reads Archive (http://www.ncbi.nlm.nih.gov/sra website) under accession number SRP045693.

\section{Additional files}

Additional file 1: Figure S2. Validation of sequencing data by $q R T-P C R$. Additional file 2: Table S10. Validation data for several key $\mathrm{Cd}$-responsive genes.

Additional file 3: Table S11. Oligonucleotide primers used in Real-time PCR assays in this study.

Additional file 4: Table S1. Sequencing results for small RNAs from four libraries.

Additional file 5: Table S2. Distribution of small RNAs among 11 different categories.

Additional file 6: Table S3. Differentially-expressed miRNAs in response to $\mathrm{Cd}$ stress in root libraries.

Additional file 7: Table S4. Differentially-expressed miRNAs in response to $\mathrm{Cd}$ stress in shoot libraries.

Additional file 8: Table S5. Identified new miRNA candidates in library $\mathrm{KR}, \mathrm{CR}, \mathrm{KS}$ and $\mathrm{CS}$.

Additional file 9: Table S6. The basical information for the precursor of the new miRNAs' candidates

Additional file 10: Figure $\mathbf{S 1}$. The accumulation of genes mapped by all clean tags and unique clean tags in five libraries.

Additional file 11: Table S7. List of DEGs in phytohormone signaling pathways.

Additional file 12: Table S8. Predicted targets for differentially expressed miRNAs based on starBase and miRBase database searches in root and shoot.
Additional file 13: Table S9. The predicted targets for the new miRNA candidates using UEA sRNA toolkit.

Additional file 14: Figure S3. The change of $A B A$ content under $C d$ stress in shoots.

\section{Competing interests}

The authors declare that they have no competing interests.

\section{Authors' contributions}

CC and DM conceived and designed the experiments. MT, DM and LX performed the experiments. MT, SS and DL analyzed the data. MT and CC wrote the manuscript. All authors read and approved the final manuscript.

\section{Acknowledgements}

The authors would like to appreciate David Zaitlin and Rocha Pedro for critical reading of the manuscript. This work was jointly supported by the Chinese Academy of Sciences (the 100-Talents Scheme) and by the National Natural Science Foundation of China (31270426 and 31371603 and 31470443).

\section{Author details}

'Key Laboratory of Agro-ecological Processes in Subtropical Region, Institute of Subtropical Agriculture, Chinese Academy of Sciences, Changsha 410125, China. ${ }^{2}$ State Key Laboratory of Plant Genomics, Institute of Genetics and Developmental Biology, Chinese Academy of Sciences, Beijing 100101, China. ${ }^{3}$ Key Laboratory of Genome Sciences and Information, Beijing Institute of Genomics, Chinese Academy of Sciences, Beijing 100029, China

Received: 20 April 2014 Accepted: 24 September 2014 Published: 1 October 2014

\section{References}

1. Bertin $G$, Averbeck D: Cadmium: cellular effects, modifications of biomolecules, modulation of DNA repair and genotoxic consequences (a review). Biochimie 2006, 88(11):1549-1559.

2. Nawrot T, Plusquin M, Hogervorst J, Roels HA, Celis H, Thijs L, Vangronsveld J, Van Hecke E, Staessen JA: Environmental exposure to cadmium and risk of cancer: a prospective population-based study. Lancet Oncol 2006, 7(2):119-126.

3. Watanabe T, Shimbo S, Moon C-S, Zhang Z-W, Ikeda M: Cadmium contents in rice samples from various areas in the world. Sci Total Environ 1996, 184(3):191-196.

4. Bartel DP: MicroRNAs: genomics, biogenesis, mechanism, and function. Cell 2004, 116(2):281-297.

5. Guo H-S, Xie Q, Fei J-F, Chua N-H: MicroRNA directs mRNA cleavage of the transcription factor NAC1 to downregulate auxin signals for Arabidopsis lateral root development. Plant Cell 2005, 17(5):1376-1386.

6. Palatnik JF, Allen E, Wu X, Schommer C, Schwab R, Carrington JC, Weigel D: Control of leaf morphogenesis by microRNAs. Nature 2003, 425(6955):257-263.

7. Aukerman MJ, Sakai H: Regulation of flowering time and floral organ identity by a microRNA and its APETALA2-like target genes. Plant Cell 2003, 15(11):2730-2741.

8. Sunkar R, Kapoor A, Zhu J-K: Posttranscriptional induction of two Cu/Zn superoxide dismutase genes in Arabidopsis is mediated by downregulation of miR398 and important for oxidative stress tolerance. Plant Cell 2006, 18(8):2051-2065.

9. Abdel-Ghany SE, Pilon M: MicroRNA-mediated systemic down-regulation of copper protein expression in response to low copper availability in Arabidopsis. J Biol Chem 2008, 283(23):15932-15945.

10. Kawashima CG, Matthewman CA, Huang S, Lee BR, Yoshimoto N, Koprivova A, Rubio-Somoza I, Todesco M, Rathjen T, Saito K: Interplay of SLIM1 and miR395 in the regulation of sulfate assimilation in Arabidopsis. Plant J 2011, 66(5):863-876.

11. Fujii H, Chiou T-J, Lin S-I, Aung K, Zhu J-K: A miRNA involved in phosphatestarvation response in Arabidopsis. Curr Biol 2005, 15(22):2038-2043.

12. Liu H-H, Tian X, Li Y-J, WU C-A, Zheng C-C: Microarray-based analysis of stress-regulated microRNAs in Arabidopsis thaliana. RNA 2008, 14(5):836-843

13. Ding Y, Chen Z, Zhu C: Microarray-based analysis of cadmium-responsive microRNAs in rice (Oryza sativa). J Exp Bot 2011, 62(10):3563-3573. 
14. Huang SQ, Peng J, Qiu CX, Yang ZM: Heavy metal-regulated new microRNAs from rice. J Inorg Biochem 2009, 103(2):282-287.

15. Ding Y, Qu A, Gong S, Huang S, Lv B, Zhu C: Molecular identification and analysis of Cd-responsive microRNAs in rice. J Agric Food Chem 2013 61(47):11668-11675.

16. Zhou ZS, Huang SQ, Yang ZM: Bioinformatic identification and expression analysis of new microRNAs from Medicago truncatula. Biochem Biophys Res Commun 2008, 374(3):538-542.

17. Herbette S, Taconnat L, Hugouvieux V, Piette L, Magniette M-L, Cuine S, Auroy P, Richaud P, Forestier C, Bourguignon J: Genome-wide transcriptome profiling of the early cadmium response of Arabidopsis roots and shoots. Biochimie 2006, 88(11):1751-1765.

18. ROMERO-PUERTAS M, RODRÍGUEZ-SERRANO M, Corpas F, Gomez M, Del Rio L Sandalio L: Cadmium-induced subcellular accumulation of $\mathrm{O}_{2}^{--}$and $\mathrm{H}_{2} \mathrm{O}_{2}$ in pea leaves. Plant Cell Environ 2004, 27(9):1122-1134.

19. Sandalio L, Dalurzo H, Gomez M, Romero-Puertas M, Del Rio L: Cadmium-induced changes in the growth and oxidative metabolism of pea plants. J Exp Bot 2001, 52(364):2115-2126.

20. Benavides MP, Gallego SM, Tomaro ML: Cadmium toxicity in plants. Braz Plant Physiol 2005, 17(1):21-34.

21. Clemens S, Palmgren MG, Krämer U: A long way ahead: understanding and engineering plant metal accumulation. Trends Plant Sci 2002, 7(7):309-315.

22. Cobbett CS: Phytochelatins and their roles in heavy metal detoxification. Plant Physiol 2000, 123(3):825-832.

23. Ogawa I, Nakanishi H, Mori S, Nishizawa NK: Time course analysis of gene regulation under cadmium stress in rice. Plant Soil 2009, 325(1-2):97-108.

24. Zhou ZS, Zeng HQ, Liu ZP, Yang ZM: Genome-wide identification of Medicago truncatula microRNAs and their targets reveals their differential regulation by heavy metal. Plant Cell Environ 2012, 35(1):86-99.

25. Zhou ZS, Song JB, Yang ZM: Genome-wide identification of Brassica napus microRNAs and their targets in response to cadmium. J Exp Bot 2012, 63(12):4597-4613.

26. Wei Y, Chen S, Yang P, Ma Z, Kang L: Characterization and comparative profiling of the small RNA transcriptomes in two phases of locust. Genome Biol 2009, 10(1):R6.

27. Wang L, Liu H, Li D, Chen H: Identification and characterization of maize microRNAs involved in the very early stage of seed germination. BMC Genomics 2011, 12(1):154.

28. Han Y, Chen J, Zhao X, Liang C, Wang Y, Sun L, Jiang Z, Zhang Z, Yang R, Chen J: MicroRNA expression signatures of bladder cancer revealed by deep sequencing. PLoS One 2011, 6(3):e18286.

29. Li R, Yu C, Li Y, Lam T-W, Yiu S-M, Kristiansen K, Wang J: SOAP2: an improved ultrafast tool for short read alignment. Bioinformatics 2009, 25(15):1966-1967.

30. Burge SW, Daub J, Eberhardt R, Tate J, Barquist L, Nawrocki EP, Eddy SR, Gardner PP, Bateman A: Rfam 11.0: 10 years of RNA families. Nucleic Acids Res 2013, 41(D1):D226-D232.

31. Kozomara A, Griffiths-Jones S: miRBase: integrating microRNA annotation and deep-sequencing data. Nucleic Acids Res 2011, 39(suppl 1):D152-D157.

32. Kozomara A, Griffiths-Jones S: miRBase: annotating high confidence microRNAs using deep sequencing data. Nucleic Acids Res 2014, 42(D1):D68-D73.

33. Li Y, Zhang Z, Liu F, Vongsangnak W, Jing Q, Shen B: Performance comparison and evaluation of software tools for microRNA deepsequencing data analysis. Nucleic Acids Res 2012, 40(10):4298-4305.

34. Moxon S, Schwach F, Dalmay T, MacLean D, Studholme DJ, Moulton V: A toolkit for analysing large-scale plant small RNA datasets. Bioinformatics 2008, 24(19):2252-2253

35. A.C.'t Hoen P, Ariyurek $Y$, Thygesen $H H$, Vreugdenhil $E$, Vossen $\mathrm{RH}_{\text {, }}$ De Menezes RX, Boer JM, Van Ommen G-JB, Den Dunnen JT: Deep sequencing-based expression analysis shows major advances in robustness, resolution and inter-lab portability over five microarray platforms. Nucleic Acids Res 2008, 36(21):e141-e141.

36. Du Z, Zhou X, Ling Y, Zhang Z, Su Z: agriGO: a GO analysis toolkit for the agricultural community. Nucleic Acids Res 2010, 38(suppl 2):W64-W70.

37. Kanehisa M, Araki M, Goto S, Hattori M, Hirakawa M, Itoh M, Katayama T, Kawashima S, Okuda S, Tokimatsu T: KEGG for linking genomes to life and the environment. Nucleic Acids Res 2008, 36(suppl 1):D480-D484.

38. Kanehisa M, Goto S: KEGG: kyoto encyclopedia of genes and genomes. Nucleic Acids Res 2000, 28(1):27-30.
39. Eisen MB, Spellman PT, Brown PO, Botstein D: Cluster analysis and display of genome-wide expression patterns. Proc Natl Acad Sci 1998, 95(25):14863-14868

40. Kawahara Y, de la Bastide M, Hamilton J, Kanamori H, McCombie WR, Ouyang S, Schwartz D, Tanaka T, Wu J, Zhou S: Improvement of the Oryza sativa Nipponbare reference genome using next generation sequence and optical map data. Rice 2013, 6(1):1-10.

41. Wang Y-P, Li K-B: Correlation of expression profiles between microRNAs and mRNA targets using NCl-60 data. Bmc Genomics 2009, 10(1):218

42. Cheng C, Li LM: Inferring microRNA activities by combining gene expression with microRNA target prediction. PloS One 2008, 3(4):e1989.

43. Zhang Z, Yu J, Li D, Zhang Z, Liu F, Zhou X, Wang T, Ling Y, Su Z: PMRD: plant microRNA database. Nucleic Acids Res 2010, 38(suppl 1):D806-D813.

44. Yang J-H, Li J-H, Shao P, Zhou H, Chen Y-Q, Qu L-H: starBase: a database for exploring microRNA-mRNA interaction maps from Argonaute CLIP-Seq and Degradome-Seq data. Nucleic Acids Res 2011, 39(suppl 1):D202-D209.

45. Sunkar R, Zhou X, Zheng Y, Zhang W, Zhu J-K: Identification of novel and candidate miRNAs in rice by high throughput sequencing. BMC Plant Biol 2008, 8(1):25.

46. Delhaize E, Ryan PR: Aluminum toxicity and tolerance in plants. Plant Physiol 1995, 107(2):315.

47. Sanita Di Toppi L, Gabbrielli R: Response to cadmium in higher plants. Environ Exp Bot 1999, 41(2):105-130

48. DalCorso G, Farinati S, Maistri S, Furini A: How plants cope with cadmium staking all on metabolism and gene expression. J Integr Plant Biol 2008, 50(10):1268-1280

49. Lin C-Y, Trinh NN, Fu S-F, Hsiung Y-C, Chia L-C, Lin C-W, Huang H-J: Comparison of early transcriptome responses to copper and cadmium in rice roots. Plant Mol Biol 2013, 81(4-5):507-522.

50. Weber M, Trampczynska A, Clemens S: Comparative transcriptome analysis of toxic metal responses in Arabidopsis thaliana and the $\mathrm{Cd}(2+)$-hypertolerant facultative metallophyte Arabidopsis halleri. Plant Cell Environ 2006, 29(5):950-963.

51. Suzuki N, Koizumi N, Sano H: Screening of cadmium-responsive genes in Arabidopsis thaliana. Plant Cell Environ 2001, 24(11):1177-1188.

52. Korobeinikova A, Garber M, Gongadze G: Ribosomal proteins: structure, function, and evolution. Biochemistry (Mosc) 2012, 77(6):562-574.

53. Bae W, Chen X: Proteomic study for the cellular responses to $\mathrm{Cd} 2+$ in Schizosaccharomyces pombe Through amino acid-coded mass tagging and liquid chromatography tandem mass spectrometry. Mol Cell Proteomics 2004, 3(6):596-607.

54. Sormani R, Masclaux-Daubresse C, Daniele-Vedele F, Chardon F: Transcriptional regulation of ribosome components are determined by stress according to cellular compartments in Arabidopsis thaliana. PloS One 2011, 6(12):e28070

55. Howitt CA, Pogson BJ: Carotenoid accumulation and function in seeds and non-green tissues. Plant Cell Environ 2006, 29(3):435-445.

56. Fernández R, Bertrand A, Reis R, Mourato MP, Martins LL, González A: Growth and physiological responses to cadmium stress of two populations of Dittrichia viscosa (L.) Greuter. J Hazard Mater 2013, 244-245:555-562.

57. Jiang H-p, Gao B-b, Li W-h, Zhu M, Zheng C-f, Zheng Q-s, Wang C-h: Physiological and Biochemical Responses of Ulva prolifera and Ulva linza to Cadmium Stress. Sci World J 2013, 2013:11.

58. LU S, Li L: Carotenoid metabolism: biosynthesis, regulation, and beyond J Integr Plant Biol 2008, 50(7):778-785

59. Li S-W, Leng Y, Feng L, Zeng X-Y: Involvement of abscisic acid in regulating antioxidative defense systems and IAA-oxidase activity and improving adventitious rooting in mung bean [Vigna radiata (L.) Wilczek] seedlings under cadmium stress. Environ Sci Pollut Res 2014, 21(1):525-537.

60. F-b W, Dong J, Jia G-X, Zheng S-j, Zhang G-p: Genotypic difference in the responses of seedling growth and $\mathrm{Cd}$ toxicity in rice (Oryza sativa L.). Agric Sci China 2006, 5(1):68-76.

61. Rhoades MW, Reinhart BJ, Lim LP, Burge CB, Bartel B, Bartel DP: Prediction of plant microRNA targets. Cell 2002, 110(4):513-520.

62. Brodersen P, Sakvarelidze-Achard L, Bruun-Rasmussen M, Dunoyer P, Yamamoto $Y Y$, Sieburth L, Voinnet O: Widespread translational inhibition by plant miRNAs and siRNAs. Science 2008, 320(5880):1185-1190.

63. Pei H, Ma N, Chen J, Zheng Y, Tian J, Li J, Zhang S, Fei Z, Gao J: Integrative analysis of miRNA and mRNA profiles in response to ethylene in rose petals during flower opening. PloS One 2013, 8(5):e64290. 
64. Thoden JB, Hegeman AD, Wesenberg G, Chapeau MC, Frey PA, Holden HM: Structural analysis of UDP-sugar binding to UDP-galactose 4-epimerase from Escherichia coli. Biochemistry 1997, 36(21):6294-6304.

65. Fusco N, Micheletto L, Dal Corso G, Borgato L, Furini A: Identification of cadmium-regulated genes by CDNA-AFLP in the heavy metal accumulator Brassica juncea L. J Exp Bot 2005, 56(421):3017-3027.

66. Van de Mortel JE, Schat H, Moerland PD, Van Themaat EVL, van der Ent S, Blankestijn H, Ghandilyan A, Tsiatsiani S, Aarts MG: Expression differences for genes involved in lignin, glutathione and sulphate metabolism in response to cadmium in Arabidopsis thaliana and the related $\mathrm{Zn/Cd-hyperaccumulator}$ Thlaspi caerulescens. Plant Cell Environ 2008, 31(3):301-324

doi:10.1186/1471-2164-15-835

Cite this article as: Tang et al:: Integrated analysis of miRNA and mRNA expression profiles in response to Cd exposure in rice seedlings. BMC Genomics 2014 15:835.

\section{Submit your next manuscript to BioMed Central and take full advantage of:}

- Convenient online submission

- Thorough peer review

- No space constraints or color figure charges

- Immediate publication on acceptance

- Inclusion in PubMed, CAS, Scopus and Google Scholar

- Research which is freely available for redistribution 